\title{
Sensitivity Analysis of the Surface Acoustic Wave Sensor towards Size-Distributed Particulate Matter
}

\author{
Jian Yang $\mathbb{D}^{\mathrm{D}}$, Jianan Lu, Shanmeng Zhang, and Dong Guan \\ College of Mechanical Engineering, Yangzhou University, Yangzhou 225127, China \\ Correspondence should be addressed to Jian Yang; yangjian204@hotmail.com
}

Received 30 November 2020; Revised 7 December 2020; Accepted 17 December 2020; Published 23 December 2020

Academic Editor: Chengwei Fei

Copyright (c) 2020 Jian Yang et al. This is an open access article distributed under the Creative Commons Attribution License, which permits unrestricted use, distribution, and reproduction in any medium, provided the original work is properly cited.

\begin{abstract}
To study the sensitivity of the surface acoustic wave (SAW) sensor towards particulate matter (PM), an analytic model has been built based on single particle perturbation theory of full size range and the lognormal size distribution of the PM. The sensitivity of the frequency shift to 1 nanogram of PM has been calculated. The model shows that the frequency shift is a result of the competition between the negative perturbation by mass loading and the positive perturbation by elastic coupling, determined by particle size distribution parameters, material, and SAW frequency. To verify the model, the relationship of the frequency shift of a $315 \mathrm{MHz}$ SAW to the concentration of aerosols generated by two kinds of powders of different sizes was measured. The experiment is in agreement with the model: the sensor has shown negative sensitivity towards aerosols generated by the finer particles of $1 \mu \mathrm{m}, 3 \mu \mathrm{m}$ polytetrafluoroethylene (PTFE), and A1 Arizona dust and positive sensitivity towards aerosols generated by the coarser particles of $10 \mu \mathrm{m}$ PTFE and A4 Arizona dust; and the negative sensitivity is about 1 order higher than the positive.
\end{abstract}

\section{Introduction}

Particulate matter (PM), known as atmospheric aerosol particles, is a key air pollutant brought into the air by a variety of natural and anthropogenic sources. The exposure to PM by human can cause asthma, lung cancer, respiratory diseases, cardiovascular disease, premature delivery, and premature death [1-4]. The size distribution of PM is important because finer particles are more toxic [5]. PMmonitoring instruments are generally based on optical and gravity methods. The optical method uses the principles of light scattering or absorption, with the instruments such as the scattering photometer, optical particle counter, and aethalometer [6-9]. The basic gravity method samples PM onto filter media with laboratory weighing before and after drawing air through the filter $[10,11]$ and, therefore, not suitable for real-time monitoring. Other gravity methods use a piezoelectric oscillation component to measure PM concentration based on the change of the resonance frequency due to the mass loading effect by the sampled PM. The oscillation component includes the tapered element oscillation microbalance (TEOM) and silicon resonant cantilever
[12-15]. As the development of the PM monitoring device that is portable, cheap, and easy to use becomes an important task, more instruments based on quartz crystal microbalance (QCM), surface acoustic wave (SAW), and film bulk acoustic resonator (FBAR) as the oscillation component have been reported [16-21]. Due to the higher operation frequency, the SAW exhibits higher sensitivity than the QCM [22].

It should be mentioned that the pursuing of use of highfrequency devices for PM measurement is risky. Since PM is size distributed, it always contains larger particles with lower resonance frequencies. Classical theory of the frequency decrease due to mass perturbation cannot be applied to the case where the sensor frequency goes beyond the resonance frequency of the coupled particle [23]. For the dynamic contact of spherical bodies, Guan employed fractal theory to investigate the conformal contact between the piston and cylinder [24, 25]. It is evident by Ramakrishnan's experiment that by controlling the height of the micropillar attached on the SAW surface, an increase of the SAW resonance frequency could be observed [26, 27]. The interaction between the SAW and particles can be modelled as a dynamic multicomponent structure, and the perturbation theory in a 
full particle size range is the key to the problem [28-31]. Cheng proposed a method using the assembly relationship to solve complex machinery of multicomponent $[32,33]$. The particle perturbation theory was firstly proposed by Dybwad who modelled the QCM-particle interaction as a coupled oscillator system, where the QCM measures either the additional mass or additional stiffness of the particles, depending on the particle size [34]. As for the SAW, our group has demonstrated that, for SAW operating at $260 \mathrm{MHz}$ measuring potato starch granules sized between 5 and $100 \mu \mathrm{m}$, the phenomenon of positive frequency shift due to the coupled stiffness has been found, and the relationship between the frequency increase and the particle size in an elastic regime was analytically derived [35]. Besides, we have built a particle-SAW coupled resonance model using the finite element method to study the size-related sensitivity of the $260 \mathrm{MHz}$ SAW in the full particle size range [36]. The limitation of our previous works is that the models were based on the interaction between SAW and single particle. To study SAW sensitivity towards PM, a size-distributed perturbation model needs to be built.

In this paper, the sensitivity of the surface acoustic wave sensor towards size-distributed particulate matter is studied. An analytic model is built based on single particle perturbation theory of full size range and the lognormal size distribution of the PM. Then, the sensitivities of the frequency shift to $1 \mathrm{ng}$ PTFE are calculated with different distribution parameters. The effects to the sensitivity by particle material and SAW operation frequency have also been taken into consideration. Finally, we present our measurement of a $315 \mathrm{MHz} \mathrm{SAW}$ towards particulates of PTFE and Arizona dust of different size distributions.

\section{Modeling}

2.1. Single-Particle Perturbation. The model of the Rayleightype SAW perturbed by a single particle is shown in Figure 1. Under van der Waals force, the particle is attached to the SAW surface and undergoes forced vibration excited by periodic displacement of the SAW at the interface. The interaction could cause negative or positive frequency shift of the SAW resonance frequency, depending on the size of the particle.

For finer particles of the size below the resonance diameter $d_{p R}$, the frequency change is expressed as follows [22]:

$$
\Delta f=-\sum_{i=1}^{3} \frac{2 \pi c_{i} f^{2} m}{A}
$$

where $c_{i}$, listed in Table 1 , is the coupling coefficient of the $i$ th direction, with the subscripted indices $i$ with values of 1,2 , and 3 refer to the $\mathrm{x}^{-}, \mathrm{y}^{-}$, and $\mathrm{z}$-direction, respectively, $m$ is mass of the particle, $f$ is SAW operation frequency, and $A$ is the sensing area of the SAW.

In this case, the particle is rigidly adhered on the SAW surface and perturbs the sensor by its own mass, leading to a decrease of SAW resonance frequency. For single particle with diameter of $d_{p}$, equation (1) could be written as

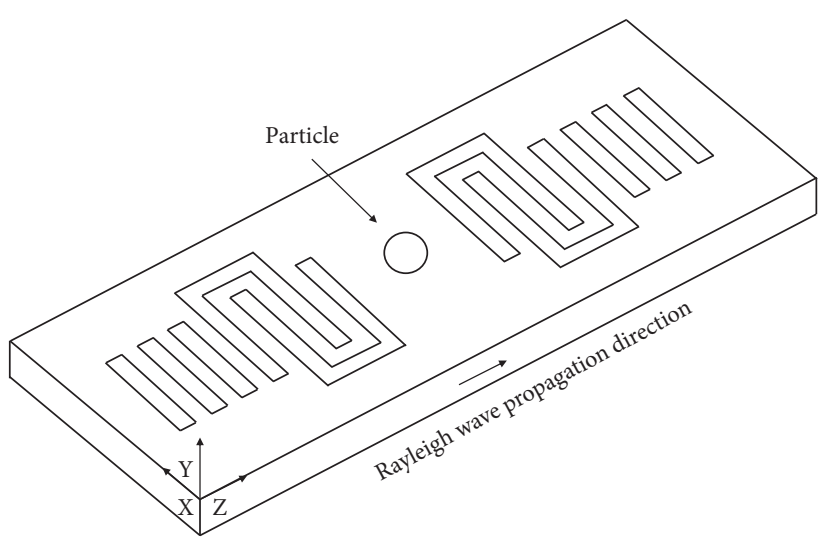

Figure 1: Particle-SAW interaction system.

TABle 1: Coupling coefficients for Rayleigh-type SAW $\left(\times 10^{-8} \mathrm{~kg}^{-1} \mathrm{~m}^{2} \mathrm{~s}\right)$.

\begin{tabular}{lcc}
\hline$c_{1}$ & $c_{2}$ & $c_{3}$ \\
\hline 0.013 & 1.421 & 0.615 \\
\hline
\end{tabular}

$$
\Delta f=-\sum_{i=1}^{3} \frac{\pi^{2} c_{i} f^{2} \rho d_{p}^{3}}{3 A}=-C_{\text {mass }} d_{p}^{3}
$$

where $\rho$ is the density of the particle.

For coarser particles of the size above the resonance diameter $d_{p R}$, the frequency change is

$$
\Delta f=\sum_{i=1}^{3} \frac{c_{i} \kappa_{i}}{2 \pi A}
$$

where $\kappa_{i}$ is the coupling stiffness of the $i$ th direction. In this case, the particle is weakly coupled to the SAW surface via the stiffness. This additional stiffness exerted on the sensor results in an increase of SAW resonance frequency.

The calculation of $\kappa_{i}$ could be found in detail in reference [35]. Briefly, the in-plane coupling stiffness is

$$
\kappa_{1,3}=G a,
$$

and the surface-normal coupling stiffness is

$$
\kappa_{2}=\frac{E a^{4 / 3}}{2},
$$

where the effective shear modulus is

$$
G=4\left(\frac{\left(2-v_{\text {particle }}\right)\left(1+v_{\text {particle }}\right)}{E_{\text {particle }}}+\frac{\left(2-v_{\mathrm{SAW}}\right)\left(1+v_{\mathrm{SAW}}\right)}{E_{\mathrm{SAW}}}\right)^{-1},
$$

effective Young's modulus is

$$
E=\frac{4}{3}\left(\frac{1-v_{\text {particle }}^{2}}{E_{\text {particle }}}+\frac{1-v_{\text {SAW }}^{2}}{E_{\mathrm{SAW}}}\right)^{-1},
$$

and the particle-SAW contact radius is 


$$
a=\sqrt[3]{3 \sqrt{A_{\text {particle }} A_{\mathrm{SAW}}}\left(\left(1-v_{\text {particle }}^{2} / E_{\text {particle }}\right)+\left(\frac{\left.\left.1-v_{\text {SAW }}^{2} / E_{\mathrm{SAW}}\right)\right)}{8 D_{0} d_{p}^{2 / 3},}\right.\right.}
$$

where $E_{\text {particle,SAW }}, v_{\text {particle,SAW }}$, and $A_{\text {particle,SAW }}$ are elastic moduli, Poisson's ratio, and Hamaker constant of the particle or the SAW, respectively, and $D_{0}=0.165 \mathrm{~nm}$ is the cutoff distance. The properties of materials appeared in this paper are listed in Table 2. For the particle with diameter of $d_{p}$, equation (3) could be calculated and noted as

$$
\Delta f=C_{\text {elastic }} d_{p}^{2 / 3} \text {. }
$$

\subsection{Sensitivity Model of SAW Perturbed by Size-Distributed} Particulate Matter. The lognormal distribution function provides a good fit to the size distribution of particulate matter and is widely used in atmospheric applications. A lognormal mass density size distribution is defined as [37]

$$
n_{M}\left(d_{p}\right)=\frac{1}{\sqrt{2 \pi} d_{p} \ln \sigma_{g}} \exp \left(\frac{-\left(\ln d_{p}-\ln d_{g}\right)^{2}}{2 \ln ^{2} \sigma_{g}}\right),
$$

where $n_{M}\left(d_{p}\right)$ is the particle mass size distribution function, $d_{p}$ is the particle diameter, $d_{g}$ is the geometric mass mean diameter, and $\sigma_{g}$ is the geometric standard deviation. Typical parameters of lognormal distributions for PM2.5 and PM10 are listed in Table 3 [38]. The calculation involves the conversion of the particle mass size distribution $n_{M}\left(d_{p}\right)$ to the particle number size distribution $n_{N}\left(d_{p}\right)$, which is also lognormal. The geometric number mean diameter of the distribution is

$$
d_{g, n}=\exp \left(3 \ln ^{2} \sigma_{g}-\ln d_{g}\right),
$$

and the geometric standard deviation $\sigma_{g}$ is the same, so that the particle number size distribution is written as

$$
n_{N}\left(d_{p}\right)=\frac{1}{\sqrt{2 \pi} d_{p} \ln \sigma_{g}} \exp \left(\frac{-\left(\ln d_{p}-\ln d_{g, n}\right)^{2}}{2 \ln ^{2} \sigma_{g}}\right) \text {. }
$$

The size distribution functions of the particle mass and number of the typical parameters are shown in Figure 2.

The resonance diameter $d_{p R}$ is evaluated by its relationship with SAW operation frequency $f$ :

$$
2 \pi f=\sqrt{\frac{\kappa_{2}}{(1 / 6) \pi \rho d_{p R}^{3}}} .
$$

For the particulate matter of total weight of $m_{P M}$, the frequency shift due to the mass loading effect is estimated by

$$
\Delta f_{\text {mass }}=-\int_{0}^{0.5 d_{p R}} C_{\text {mass }} d_{p}^{3} \frac{m_{P M}}{\int_{-\infty}^{\infty}\left(\pi \rho d_{p}^{3} / 6\right) d d_{p}} n_{N}\left(d_{p}\right) d d_{p} .
$$

The frequency shift due to the elastic coupling effect is estimated by
TABLe 2: Properties of materials [36].

\begin{tabular}{lcccc}
\hline Material & $E(\mathrm{GPa})$ & $\nu$ & $\rho\left(\mathrm{kg} / \mathrm{m}^{-3}\right)$ & $A(\mathrm{~J})$ \\
\hline Quartz(SAW) & 73 & 0.17 & 2650 & $8.4 \times 10^{-20}$ \\
PTFE & 0.5 & 0.46 & 2200 & $5.6 \times 10^{-20}$ \\
Polystyrene & 2.4 & 0.4 & 1000 & $6.4 \times 10^{-20}$ \\
Aluminum & 70 & 0.35 & 2700 & $36.7 \times 10^{-20}$ \\
\hline
\end{tabular}

TABLE 3: Typical geometric mass mean diameter $d_{g}[\mu \mathrm{m}]$ and geometric standard deviation $\sigma_{g}$ for PM2.5 and PM10.

\begin{tabular}{lcc}
\hline & $d_{g}[\mu \mathrm{m}]$ & $\sigma_{g}$ \\
\hline PM2.5 & 0.4 & 2.2 \\
PM10 & 4.5 & 1.6 \\
\hline
\end{tabular}

$$
\Delta f_{\text {elastic }}=\int_{2 d_{p R}}^{\infty} C_{\text {elastic }} d_{p}^{2 / 3} \frac{m_{P M}}{\int_{-\infty}^{\infty}\left(\pi \rho d_{p}^{3} / 6\right) d d_{p}} n_{N}\left(d_{p}\right) d d_{p} .
$$

Since $d_{p R}$ is away from the peak of the particle number size distribution function, the possibility of $d_{p}$ falling in the transition region of $d_{p}=0.5 d_{p R} \sim 2 d_{p R}$ is low, and the frequency shift took place in this region has been ignored.

Therefore, the overall frequency shift $\Delta f_{\text {total }}$ is estimated by

$$
\Delta f_{\text {total }}=\Delta f_{\text {mass }}+\Delta f_{\text {elastic }} \text {. }
$$

\subsection{The Influence of Different Parameters to SAW Sensitivity toward $P M$}

2.3.1. Distribution Parameters. To investigate SAW response to different size-distributed particulate matter, the sensitivity of the frequency shift of a $260 \mathrm{MHz}$ SAW to $1 \mathrm{ng}$ PTFE PM2.5 and PM10 has been calculated. The geometric mass mean diameters $d_{g}$ and $\sigma_{g}$ are set around typical values $\left(d_{g}=0.2 \sim 0.6 \mu \mathrm{m}, \sigma_{g}=\right.$ 1.8 2.6 for PM2.5, and $d_{g}=3.5 \sim 6.5 \mu \mathrm{m}, \sigma_{g}=1.2 \sim 2$ for PM10), as they could vary among aerosols. The sensitivities vs. geometric mass mean diameter $d_{g}$ and $\sigma_{g}$ are shown in Figure 3. It could be seen that, for PM2.5, both the negative frequency shift perturbed by the finer particles and positive frequency shift perturbed by the coarser particles take place, and the total frequency change is a competition result between the two perturbations. As $d_{g}$ increases or $\sigma_{g}$ decreases, the frequency shift due to the elastic perturbation increases slowly, while the negative frequency shift due to the mass loading effect decreases. As a result, the sign of total frequency shift changes from the negative to the positive due to the competition between the two effects. For PM 10, as the size distribution is dominated by the coarser particles, the total frequency shift is always positive due to the elastic perturbation, and the sensitivity deceases for larger $d_{g}$ and smaller $\sigma_{g}$. Compared to the PM2.5, the sensitivity to PM 10 is 1 or 2 orders lower.

2.3.2. Particle Material. The resonance diameter $d_{p R}$ depends on the material properties of the particle. Polystyrene and aluminium have been chosen to represent stiffer 


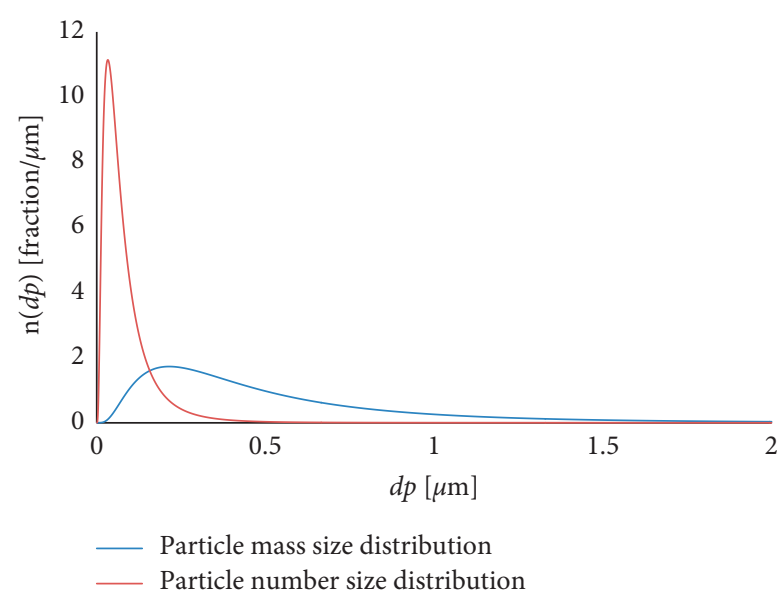

(a)

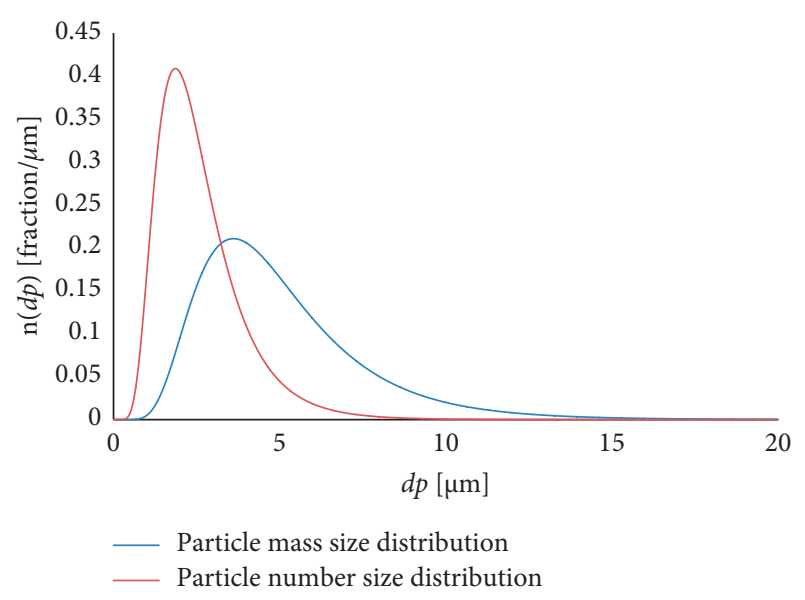

(b)

Figure 2: Particle mass and number size distribution functions of (a) PM2.5 and (b) PM10.

particulates whose resonance diameters are larger when they undergo the forced vibrations at the same frequency. Their properties are listed in Table 2. The sensitivities vs. geometric mass mean diameter $d_{g}$ of PM2.5 and PM10 of different materials are shown in Figure 4 . As the resonance diameter $d_{p R}$ increases, particles of the size below $d_{g}$ take larger proportion; therefore, more particles are involved in the mass perturbation. It can be seen in Figure 4(a) that the sensitivity curve goes downwards as the material becomes stiffer from PTFE to polystyrene and to aluminium, indicating the dominance of the mass loading effect. Note that the sensitivity increases as the material gets stiffer. As for PM10 in Figure 4(b), since particles of the size above $d_{p R}$ take the majority, the frequency shift is almost fully caused by the elastic coupling effect. The sensitivities of the three materials are similar.

2.3.3. SAW Operation Frequency. The sensitivity curve of the SAW depends on its operation frequency $f$. Substituting equation (5) into equation (13) yields the relationship between $d_{p R}$ and $f$ :

$$
d_{p R} \propto f^{-(6 / 7)}
$$

Therefore, by increasing SAW operation frequency, $d_{p R}$ decreases. Curves of sensitivity vs. geometric mass mean diameter $d_{g}$ of $260 \mathrm{MHz}$ and $520 \mathrm{MHz}$ SAW to PTFE are shown in Figure 5. As shown in (a), for PM2.5, the negative frequency shift per ng due to the mass loading effect of the two frequencies is similar. This is because, for the higher frequency sensor, the proportion of the particulate matter causing mass perturbation decreases due to the smaller $d_{p R}$, which offsets the increase of the mass sensitivity which is proportional to $f^{2}$ (as seen in equation (1)). Meanwhile, the positive frequency shift per ng due to the elastic coupling of the $520 \mathrm{MHz}$ SAW is much higher, as more particles in $1 \mathrm{ng}$ are above the size of $d_{p R}$. As a result, the total sensitivity curve moves up. For PM10, the perturbation for both sensors are elastic, where the sensitivity of the $520 \mathrm{MHz}$
SAW is higher due to the smaller sensing area compared to the $260 \mathrm{MHz}$. It should be noted that speaking of the PM concentration-based sensitivity, if the capture capability per area is constant, the larger sized $260 \mathrm{MHz}$ sensor would be loaded with almost twice as much as particles captured by the $520 \mathrm{MHz}$ one; thus, the difference between their concentration-based sensitivities is smaller.

\section{Experiment}

The schematic block diagram is shown in Figure 6. The differential frequency measurement system has been adopted to remove the common mode frequency changes. The setup is based on $315 \mathrm{MHz}$ Rayleigh-type SAW, configured as the resonance element of each side of the oscillator circuitry. The mixer followed by a low-pass filter is used to extract the differential frequency shift due to the particle perturbation. The frequency shift is recorded by the frequency counter.

A 7L PM test platform has been built, as shown in Figure 7. The sphere-shaped PTFE particles with several nominal sizes are used for PM generation. The particles were fed onto a conveyor belt driven by a stepping motor controlling the delivering speed and duration. These particles were sucked into the chamber through the Venturi tube to generate aerosol. The SAW sensor and an optical PM sensor were used for the measurement. After each measurement, the vacuum cleaner worked to clean up the chamber.

A $35 \mathrm{~m}^{3}$ PM testing room has also been built for the measurement of the standard Arizona dust, which is widely used in the development and the calibration of the optical PM sensors [39]. As shown in Figure 8, Arizona dust was dried by the light and delivered into a smaller stirring chamber where very high-concentration aerosol was generated. Then, the aerosol passed through the outlet of the stirring chamber and was diffused in the $35 \mathrm{~m}^{3}$ testing room. Both the SAW and the optical sensor were placed in the testing room for the measurement. The particulate matter were also monitored by using an optical particle sizer (TSI3330) to extract the size distribution parameters. 

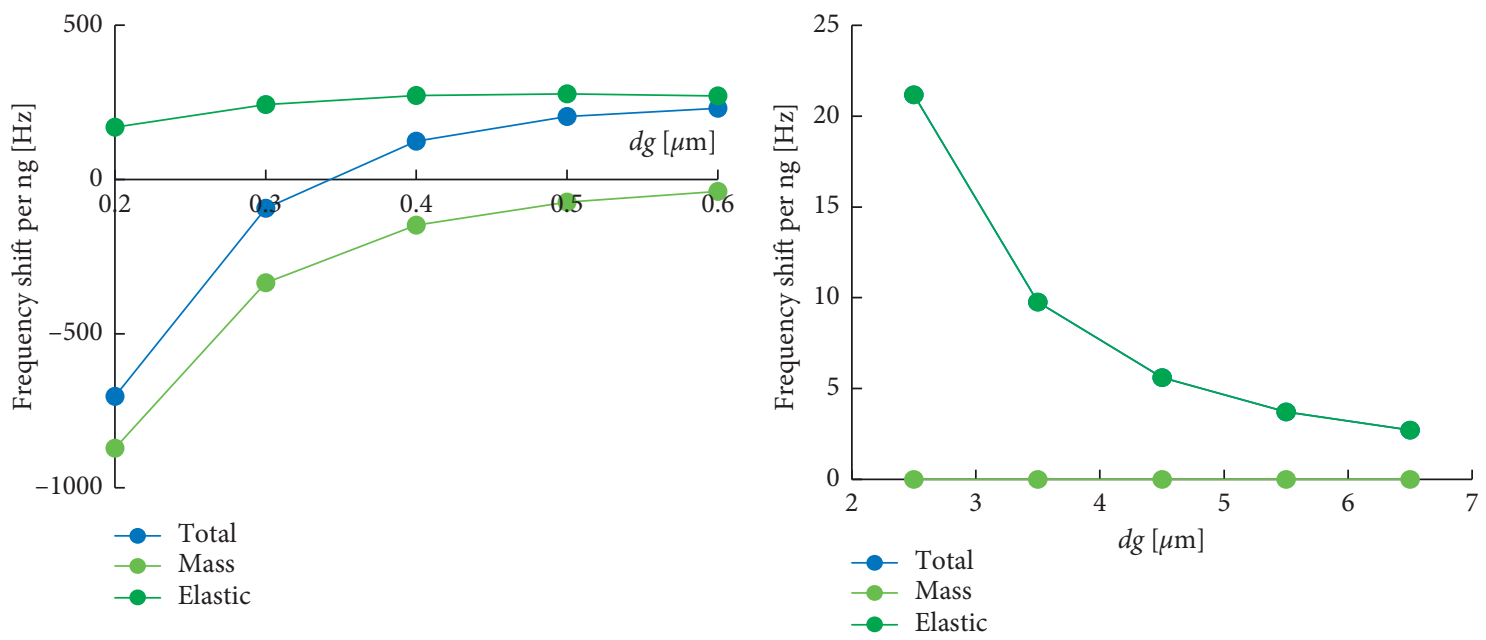

(a)
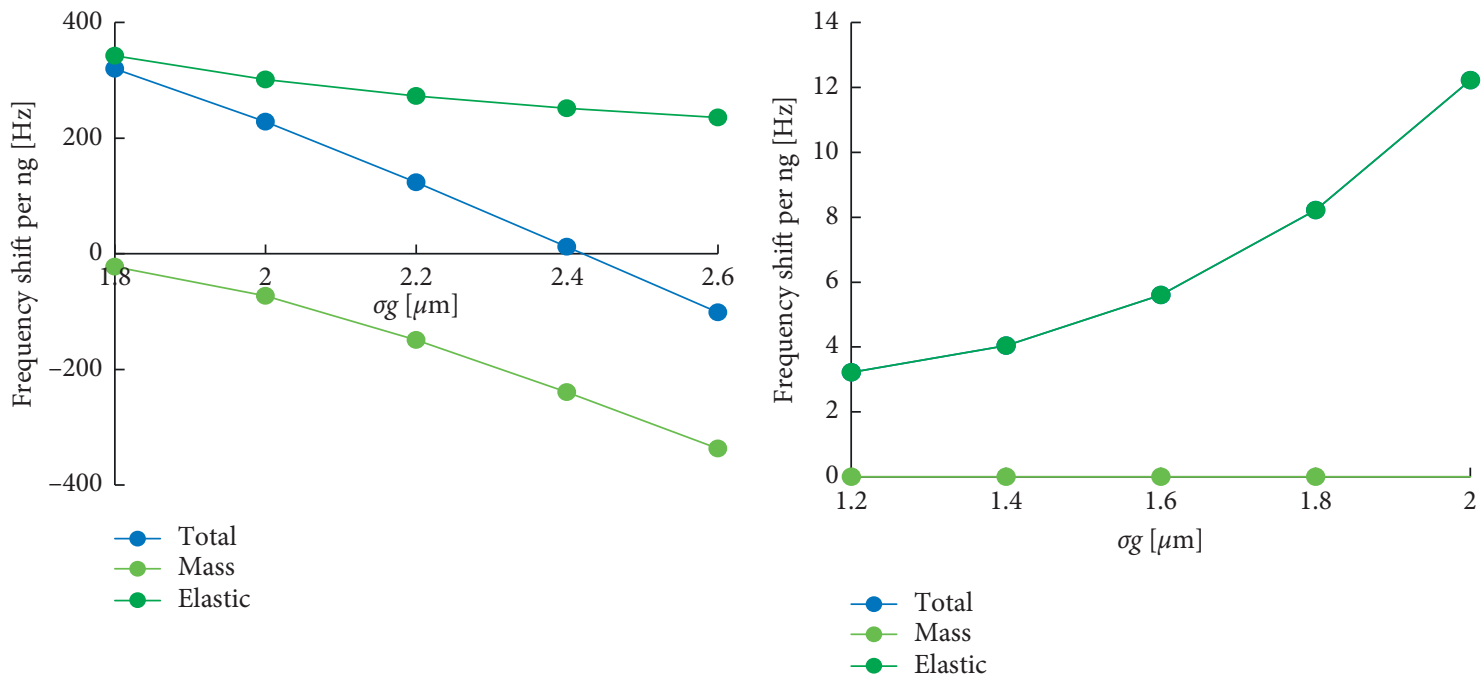

(c)

(d)

FigURE 3: SAW Sensitivity vs. geometric mass mean diameter $d_{g}$ and geometric standard deviation $\sigma_{g}$. (a) PM2.5 with $d_{g}=0.2 \sim 0.6 \mu \mathrm{m}$ and $\sigma_{g}=2.2$. (b) PM10 with $d_{g}=2.5 \sim 6.5 \mu \mathrm{m}$ and $\sigma_{g}=1.6$. (c) PM2.5 with $d_{g}=0.4 \mu \mathrm{m}$ and $\sigma_{g}=1.8 \sim 2.6$. (d) PM10 with $d_{g}=4.5 \mu \mathrm{m}$ and $\sigma_{g}=$ $1.2 \sim 2$.

\section{Result and Discussion}

The frequency shift of the SAW vs. PM concentration measured by the optical sensor to PTFE particles of different nominal sizes measured in the $7 \mathrm{~L}$ platform is shown in Figure 9. The concentration range was controlled between 200 and $800 \mu \mathrm{g} / \mathrm{m}^{3}$. For the size-distributed aerosol generated by $1 \mu \mathrm{m}$ fine PTFE particles, the sensitivity of the frequency shift per concentration was $-5.5 \mathrm{~Hz} /\left(\mu \mathrm{g} / \mathrm{m}^{3}\right)$, indicating that the perturbation was dominated by the mass loading effect. For the aerosol generated by $3 \mu \mathrm{m}$ - and $10 \mu \mathrm{m}$-coarse PTFE particles, the sensitivities were 1.1 and $0.44 \mathrm{~Hz} /\left(\mu \mathrm{g} / \mathrm{m}^{3}\right)$, respectively. It is evident that the perturbations by the particles were mostly elastic. The sensitivity to the coarse particles was much lower than that to the fine particles, and it decreased as the size increased from 3 to $10 \mu \mathrm{m}$, which matches the calculation shown in Figure 3.
The frequency shift of the SAW vs. PM concentration to A1 and A4 Arizona dust measured in the $35 \mathrm{~m}^{3}$ platform. The distribution of the A1 Arizona aerosol generated in the room was measured by using the optical particle sizer with a geometric mass mean diameter $d_{g}=0.53 \mu \mathrm{m}$ and the geometric standard deviation $\sigma_{g}=1.71$. As seen in Figure 10(a), the sensitivity was $-1.9 \mathrm{~Hz} /\left(\mu \mathrm{g} / \mathrm{m}^{3}\right)$, smaller than the $1 \mu \mathrm{m}$ PTFE sensitivity tested in the $7 \mathrm{~L}$ chamber. The reason might be that the capture of very fine particles in a room is more difficult due to the slow particle settlement speed, as well as the difference of the microstructures between the two materials. As shown in Figure 11, the shape of the PTFE particle is closer to the sphere, while it is irregular for the particle of Arizona dust. The Arizona particle couples onto the SAW surface with several asperities rather than only one contact interface like the sphere particle of PTFE. As a result, the coupling stiffness is weaker, so that the effective $d_{g R}$ is larger 


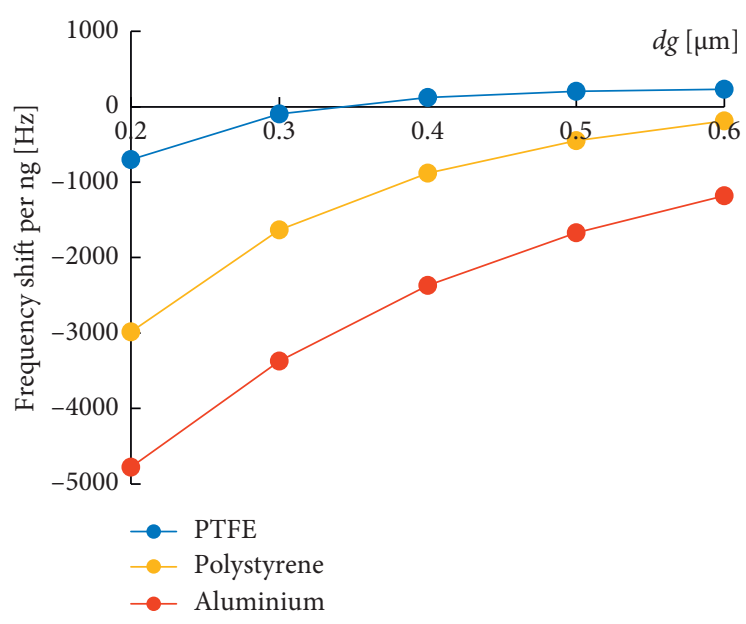

(a)

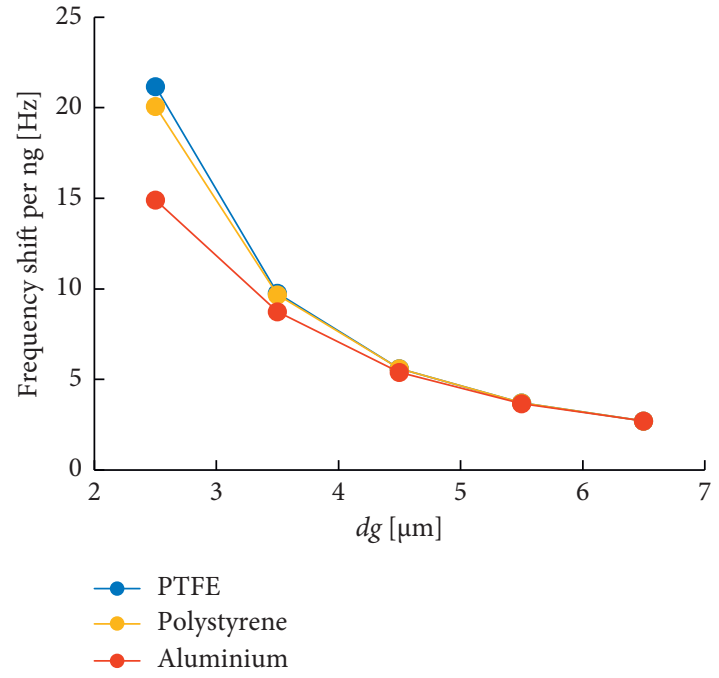

(b)

Figure 4: SAW Sensitivity vs. geometric mass mean diameter $d_{g}$ of (a) PM2.5 with $d_{g}=0.2 \sim 0.6 \mu \mathrm{m}$ and $\sigma_{g}=2.2$ and (b) PM10 with $d_{g}=2.5 \sim 6.5 \mu \mathrm{m}$ and $\sigma_{g}=1.6$ of different materials.

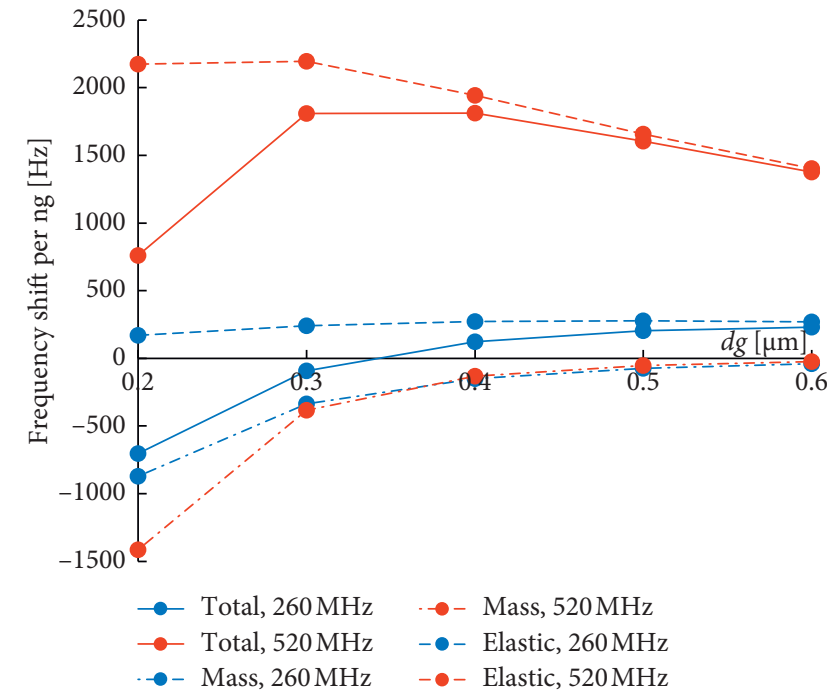

(a)

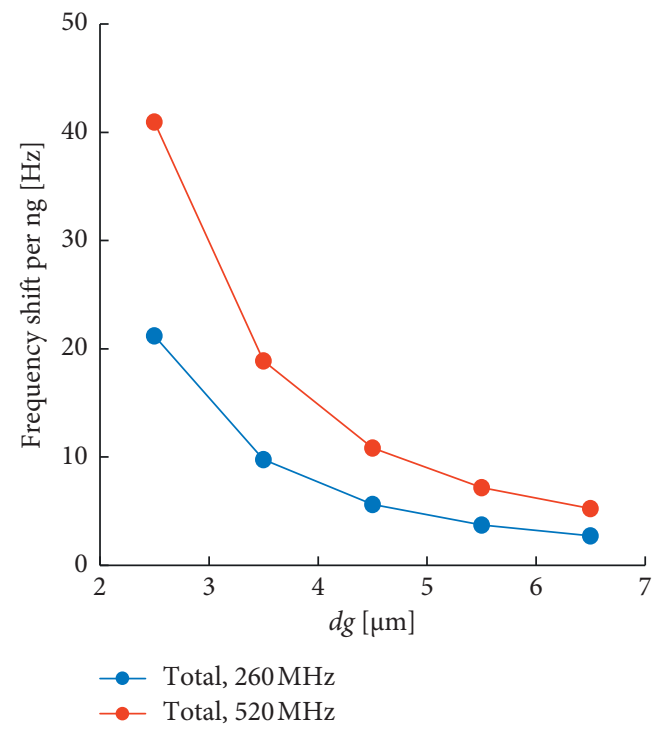

(b)

Figure 5: Sensitivity vs. geometric mass mean diameter $d_{g}$ of $260 \mathrm{MHz}$ and $520 \mathrm{MHz}$ SAW to PTFE. (a) PM2.5 with $d_{g}=0.2 \sim 0.6 \mu \mathrm{m}$ and $\sigma_{g}=2.2$ and (b) PM10 with $d_{g}=2.5 \sim 6.5 \mu \mathrm{m}$ and $\sigma_{g}=1.6$.

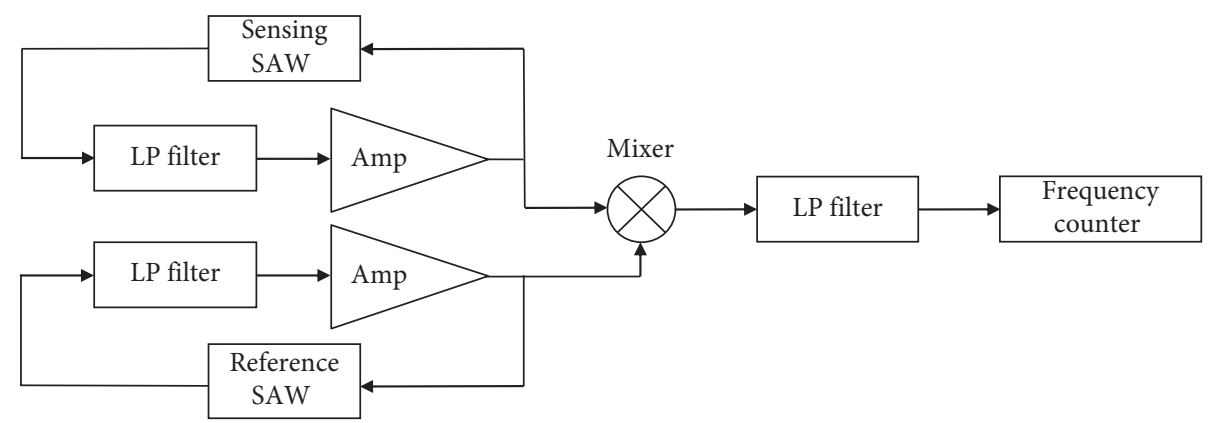

FIgURE 6: The differential frequency measurement circuitry. 


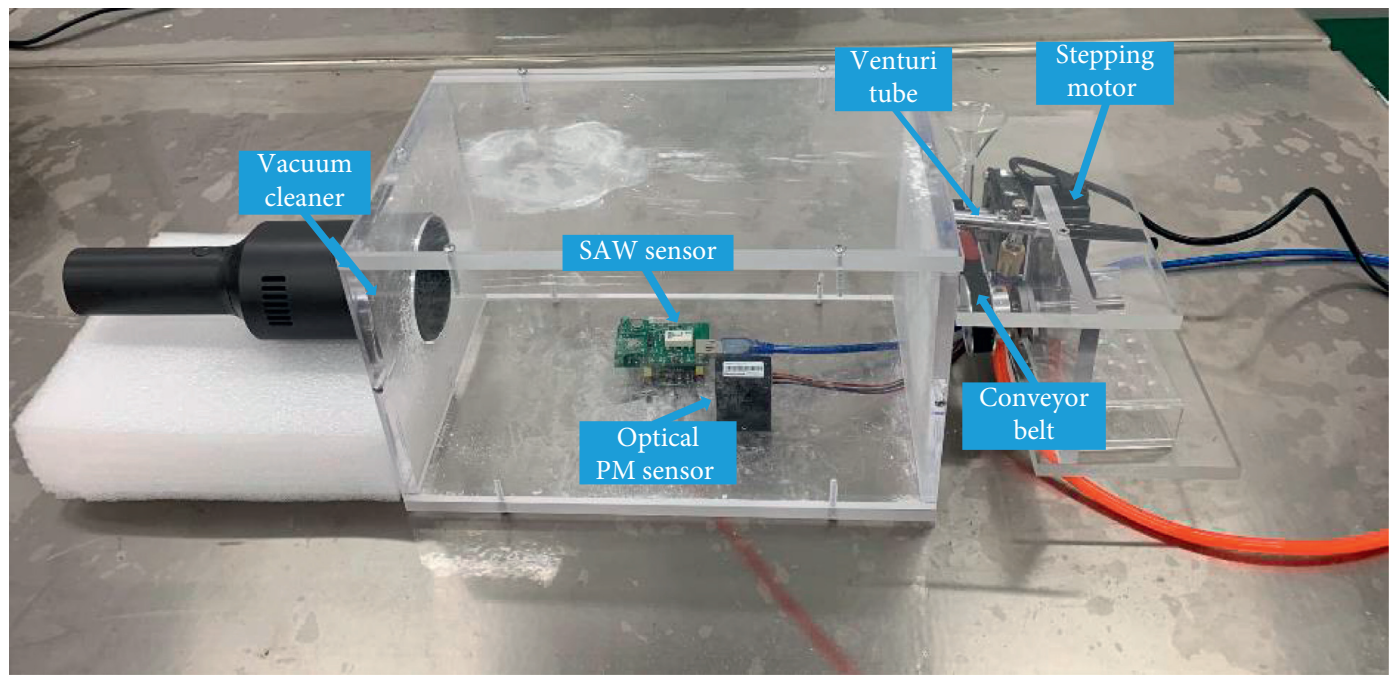

Figure 7: The setup of the 7L PM test platform.

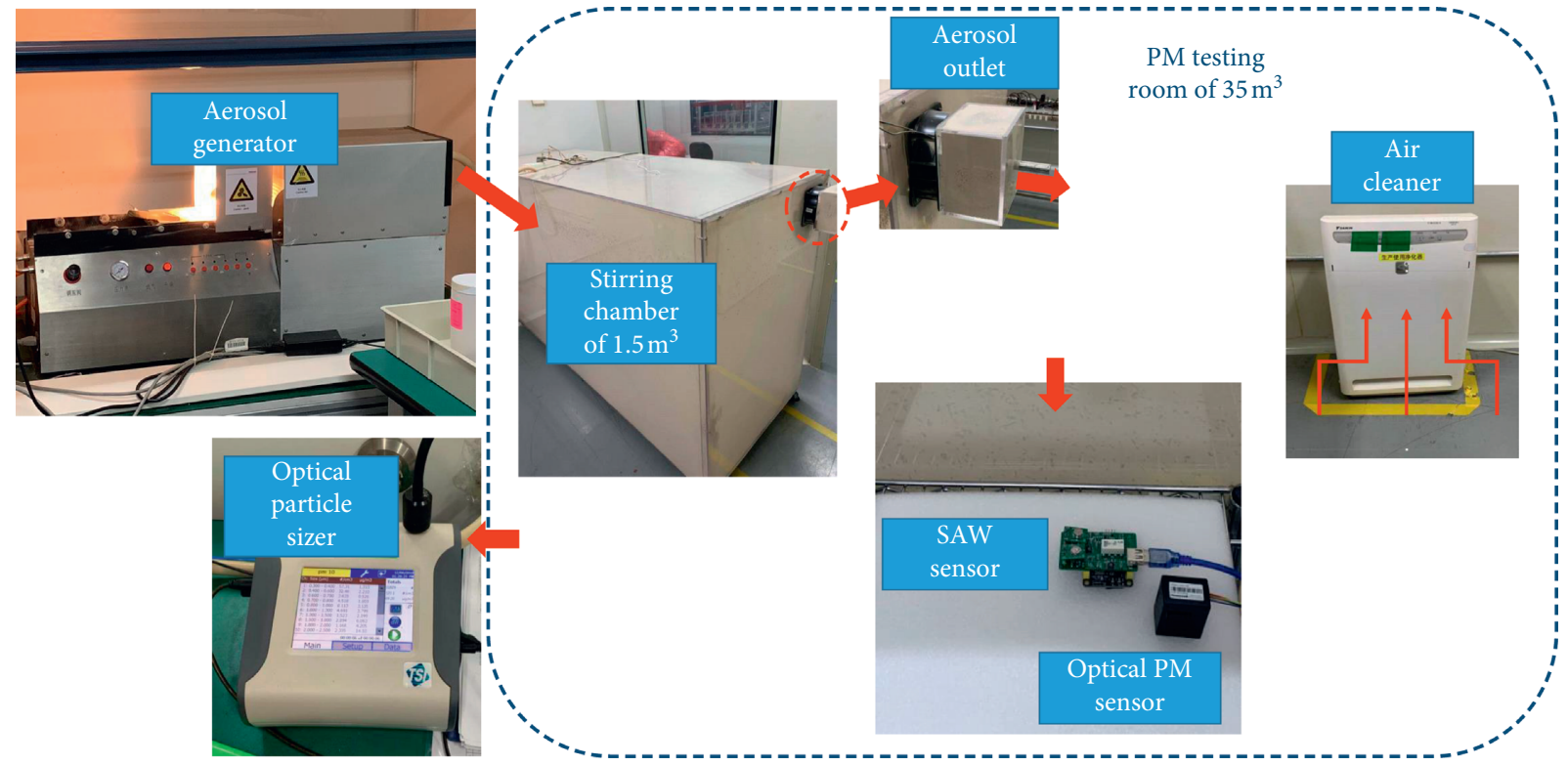

Figure 8: The setup of the $35 \mathrm{~m} 3 \mathrm{PM}$ testing room.

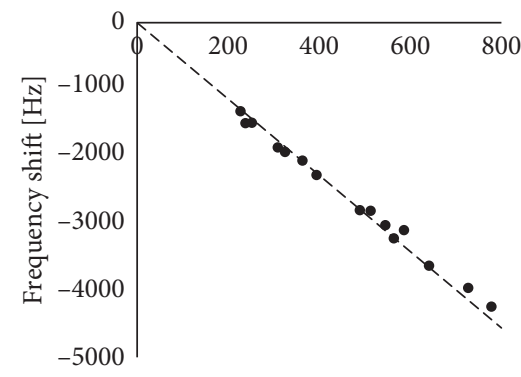

Concentration $\left[\mu \mathrm{g} / \mathrm{m}^{3}\right]$

(a)

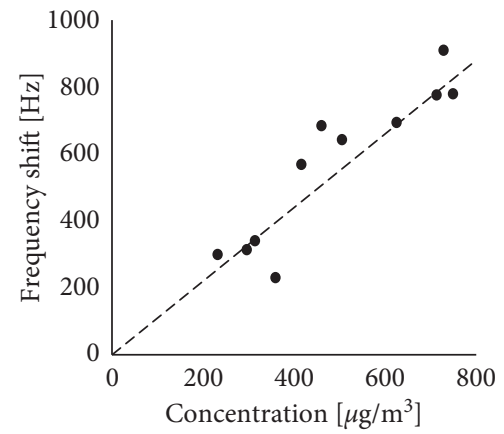

(b)

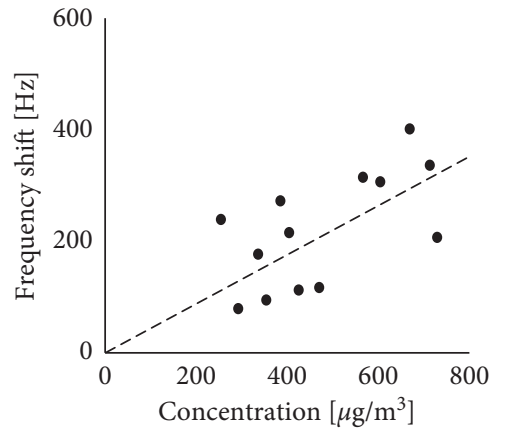

(c)

FIgURE 9: The frequency shift of the $315 \mathrm{MHz}$ SAW vs. the concentration of aerosols generated by (a) $1 \mu \mathrm{m}$, (b) $3 \mu \mathrm{m}$, and (c) $10 \mu \mathrm{m}$ PTFE particles, measured in the $7 \mathrm{~L}$ platform. 


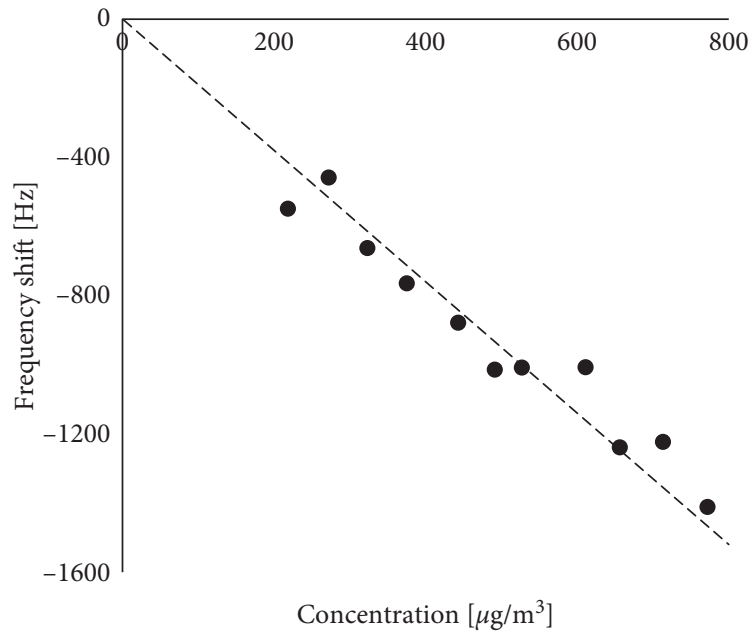

(a)

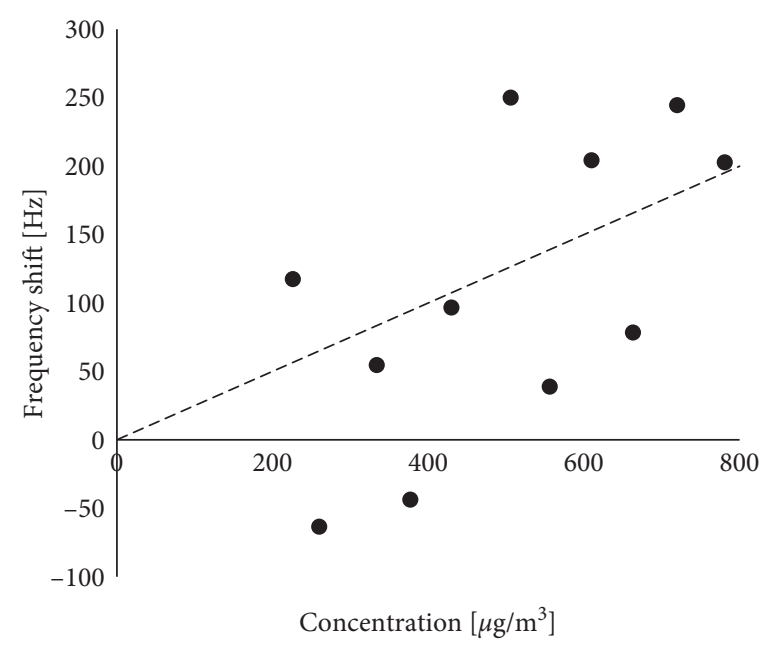

(b)

Figure 10: The frequency shift of the $315 \mathrm{MHz}$ SAW vs. the concentration of aerosols generated by (a) A1 and (b) A4 Arizona dust, measured in the $35 \mathrm{~m}^{3}$ testing room.

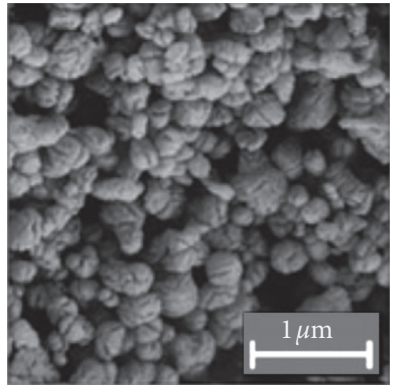

(a)

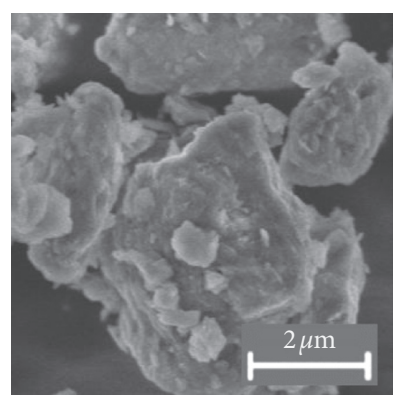

(b)

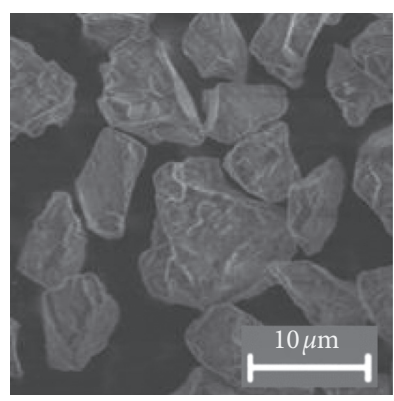

(c)

Figure 11: FESEM images of (a) $1 \mu \mathrm{m}$ PTFE, (b) A1, and (c) A4 Arizona dust.

and less proportion of Arizona particles perturb the SAW with their mass. As for the A4 Arizona dust, as shown in Figure 10(b), the sensitivity measured was about $0.25 \mathrm{~Hz} /$ $\left(\mu \mathrm{g} / \mathrm{m}^{3}\right)$ with poor linearity. It might be due to the facts that the sensitivity in the elastic region is low, and the irregular shape of the A4 Arizona particles increases the sensitivity randomness, especially for the larger sized particles, where the randomness is difficult to be reduced as the number of the particles per weight is small.

\section{Conclusions}

The sensitivity of the surface acoustic wave (SAW) sensor towards size-distributed particulate matter (PM) has been analyzed by the proposed model combining the full sizeranged perturbation theory and PM distribution function. The calculation shows that the total frequency shift is a competition result between the negative shift by the mass loading of the fine-sized fraction of the PM and the positive shift by the elastic coupling of the coarse-sized fraction, determined by particle size distribution parameters, material, and SAW frequency. The model is verified by the experiment using a $315 \mathrm{MHz}$ SAW measuring aerosols generated by polytetrafluoroethylene (PTFE) particles and Arizona dust of different sizes. The sensor has shown negative and higher sensitivity towards PM2.5-like aerosols generated by finer particles and positive and lower sensitivity towards PM10-like aerosols generated by coarser particles. The model proposed in this paper could be served as a reference for the development of PM sensors using highfrequency oscillation devices.

\section{Data Availability}

The data that support the findings of this study are available from the corresponding author upon reasonable request.

\section{Conflicts of Interest}

The authors declare that they have no conflicts of interest.

\section{Acknowledgments}

This work was funded by the National Natural Science Foundation of China (Grant no. 61701430) and the Natural Science Foundation of Jiangsu Province (No. BK20180933). 


\section{References}

[1] H. Kim, H. Kim, Y.-H. Park, and J.-T. Lee, "Assessment of temporal variation for the risk of particulate matters on asthma hospitalization," Environmental Research, vol. 156, pp. 542-550, 2017.

[2] L. Gharibvand, W. Lawrence, David Shavlik et al., "The association between ambient fine particulate matter and incident adenocarcinoma subtype of lung cancer," Environmental Health, vol. 16, no. 1, p. 71, 2017.

[3] M. Dastoorpoor, E. Idani, G. Goudarzi, and N. Khanjani, "Acute effects of air pollution on spontaneous abortion, premature delivery, and stillbirth in Ahvaz, Iran: a time-series study," Environmental Science and Pollution Research, vol. 25, no. 6, pp. 5447-5458, 2018.

[4] Q. Zeng, Y. Ni, G. Jiang, G. Li, and X. Pan, "The short term burden of ambient particulate matters on non-accidental mortality and years of life lost: a ten-year multi-district study in Tianjin, China," Environmental Pollution, vol. 220, pp. 713-719, 2017.

[5] M. Park and S. Hung, K. Lee et al., "Differential toxicities of fine particulate matters from various sources," Scientific Reports, vol. 8, no. 1, pp. 1-11, 2018.

[6] D. Chen, X. Liu, J. Han, M. Jiang, Y. Xu, and M. Xu, "Measurements of particulate matter concentration by the light scattering method: optimization of the detection angle," Fuel Processing Technology, vol. 179, pp. 124-134, 2018.

[7] C.-H. Chien, A. Theodore, C.-Y. Wu, Y.-M. Hsu, and B. Birky, "Upon correlating diameters measured by optical particle counters and aerodynamic particle sizers," Journal of Aerosol Science, vol. 101, pp. 77-85, 2016.

[8] L. R. Crilley, M. Shaw, R. Pound et al., "Evaluation of a lowcost optical particle counter (Alphasense OPC-N2) for ambient air monitoring," Atmospheric Measurement Techniques, vol. 11, no. 2, pp. 709-720, 2018.

[9] U. Dutt, N. Jiang, G. Ross, and G. Gunaratnam, "Application of the aethalometer for black carbon source analysis," Air Quality and Climate Change, vol. 52, no. 3, p. 6, 2018.

[10] B. Giechaskiel, M. Maricq, L. Ntziachristos et al., "Review of motor vehicle particulate emissions sampling and measurement: from smoke and filter mass to particle number," Journal of Aerosol Science, vol. 67, pp. 48-86, 2014.

[11] J. G. Watson, R. J. Tropp, S. D. K. Wang, S. D. Kohl, X. Wang, and J. C. Chow, "Filter processing and gravimetric analysis for suspended particulate matter samples," Aerosol Science and Engineering, vol. 1, no. 2, pp. 93-105, 2017.

[12] B. Sullivan, G. Allawatt, A. Emery, P. Means, J. Kramlich, and J. Posner, "Time-resolved particulate emissions monitoring of cookstove biomass combustion using a tapered element oscillating microbalance," Combustion Science and Technology, vol. 189, no. 6, pp. 923-936, 2017.

[13] Q.-F. Li, L. Wang-Li, Z. Liu, A. J. Heber, and Heber, "Field evaluation of particulate matter measurements using tapered element oscillating microbalance in a layer house," Journal of the Air \& Waste Management Association, vol. 62, no. 3, pp. 322-335, 2012.

[14] H. S. Wasisto, S. Merzsch, E. Uhde, A. Waag, E. Peiner, and E. Peiner, "Handheld personal airborne nanoparticle detector based on microelectromechanical silicon resonant cantilever," Microelectronic Engineering, vol. 145, pp. 96-103, 2015.

[15] Y. Bao, S. Cai, H. Yu, T. Xu, P. Xu, and X. Li, "A resonant cantilever based particle sensor with particle-size selection function," Journal of Micromechanics and Microengineering, vol. 28, no. 8, Article ID 085019, 2018.
[16] N. D. Ngo, J. Lee, M.-W. Kim, and J. Jang, "Measurement of PM2.5 mass concentration using an electrostatic particle concentrator-based quartz crystal microbalance," IEEE Access, vol. 7, pp. 170640-170647, 2019.

[17] J. Zhao, M. Liu, L. Liang, W. Wang, and J. Xie, “Airborne particulate matter classification and concentration detection based on 3D printed virtual impactor and quartz crystal microbalance sensor," Sensors and Actuators A: Physical, vol. 238, pp. 379-388, 2016.

[18] J. Liu, W. Hao, M. Liu, Y. Liang, and S. He, "A novel particulate matter 2.5 sensor based on surface acoustic wave technology," Applied Sciences, vol. 8, no. no. 1, p. 82, 2018.

[19] L. Djoumi, M. Vanotti, and V. Blondeau-Patissier, "Real time cascade impactor based on surface acoustic wave delay lines for PM10 and PM2.5 mass concentration measurement," Sensors, vol. 18, no. 1, p. 255, 2018.

[20] F.-Y. Kuo, Y.-C. Lin, L.-Y. Ke, C.-J. Tsai, and D.-J. Yao, "Detection of particulate matter of size $2.5 \mu \mathrm{m}$ with a surfaceacoustic-wave sensor combined with a cyclone separator," Micromachines, vol. 9, no. 8, p. 398, 2018.

[21] I. Paprotny, F. Doering, P. A. Solomon, R. M. White, R. M. White, and L. A. Gundel, "Microfabricated airmicrofluidic sensor for personal monitoring of airborne particulate matter: design, fabrication, and experimental results," Sensors and Actuators A: Physical, vol. 201, pp. 506516, 2013.

[22] D. S. Ballantine, R. M. White, E. T. Zellers, G. C. Frye, and H. Wohltjen, Acoustic Wave Sensors: Theory, Design and Physico-Chemical Applications, Elsevier, Amsterdam, Netherlands, 1996.

[23] N. Gao, D. Luo, B. Cheng, and H. Hou, "Teaching-learningbased optimization of a composite metastructure in the 0-10 $\mathrm{kHz}$ broadband sound absorption range," The Journal of the Acoustical Society of America, vol. 148, no. 2, pp. EL125EL129, 2020.

[24] D. Guan, L. Jing, H. H. Hilton, J. Gong, and Z. Yang, "Tangential contact analysis of spherical pump based on fractal theory," Tribology International, vol. 119, pp. 531-538, 2018.

[25] D. Guan, L. Jing, J. Gong, H. Shen, and H. H. Hilton, "Normal contact analysis for spherical pump based on fractal theory," Tribology International, vol. 124, pp. 117-123, 2018.

[26] N. Ramakrishnan, H. B. Nemade, and P. Roy, "Mass loading in coupled resonators consisting of SU-8 micropillars fabricated over SAW devices," IEEE Sensors Journal, vol. 11, no. 2, pp. 430-431, 2010

[27] N. Ramakrishnan, H. B. Nemade, and R. P. Palathinkal, "Resonant frequency characteristics of a SAW device attached to resonating micropillars," Sensors, vol. 12, no. 4, pp. 3789-3797, 2012.

[28] C. W. Fei, H. T. Liu, S. L. Li, H. Li, L. Q. An, and C. Lu, "Dynamic parametric modeling-based mdoel updating strategy of aeroengine casings," Chinese Journal of Aeronautics, 2020.

[29] C. Lu, Y.-W. Feng, C.-W. Fei, and Si-Qi Bu, "Improved decomposed-coordinated kriging modeling strategy for dynamic probabilistic analysis of multicomponent structures," IEEE Transactions on Reliability, 2019.

[30] C. Lu, C.-W. Fei, H.-T. Liu, H. Li, and L.-Q. An, "Moving extremum surrogate modeling strategy for dynamic reliability estimation of turbine blisk with multi-physics fields," Aerospace Science and Technology, vol. 106, p. 106112, 2020.

[31] C.-W. Fei, H. Li, H.-T. Liu et al., "Enhanced network learning model with intelligent operator for the motion reliability 
evaluation of flexible mechanism," Aerospace Science and Technology, vol. 107, p. 106342, 2020.

[32] C.-W. Fei, H. Li, H.-T. Liu et al., "Multilevel nested reliabilitybased design optimization with hybrid intelligent regression for operating assembly relationship," Aerospace Science and Technology, vol. 103, p. 105906, 2020.

[33] F. E. I. Chengwei, L. I. U. Haotian, Z. H. U. Zhengzheng, A. N. Liqiang, L. I. Shaolin, and L. U. Cheng, "Whole-process design and experimental validation of landing gear lower drag stay with global/local linked driven optimization strategy," Chinese Journal of Aeronautics, 2020.

[34] G. L. Dybwad, "A sensitive new method for the determination of adhesive bonding between a particle and a substrate," Journal of Applied Physics, vol. 58, no. 7, pp. 2789-2790, 1985.

[35] J. Yang and H. Chen, "A novel method of studying the microcontact using surface acoustic wave sensor," Sensor Review, 2016.

[36] J. Yang and J. Lu, "Study of size-related sensitivity of surface acoustic wave sensor towards particulate matter sized particles using finite element and experimental methods," $A I P$ Advances, vol. 10, no. 2, Article ID 025324, 2020.

[37] C. H. Jung and Y. P. Kim, "Analysis on the bias of the PM2.5 separator for polydispersed aerosol size distribution," Separation and Purification Technology, vol. 104, pp. 167-174, 2013.

[38] L. Zhang and Z. He, "Technical Note: an empirical algorithm estimating dry deposition velocity of fine, coarse and giant particles," Atmospheric Chemistry and Physics, vol. 14, no. 7, pp. 3729-3737, 2014.

[39] S. Sousan, K. Koehler, L. Hallett, T. M. Peters, and Peters, "Evaluation of consumer monitors to measure particulate matter," Journal of Aerosol Science, vol. 107, pp. 123-133, 2017. 